\title{
Ongoing outbreak of mumps infection in Oban, Scotland, November 2010 to January 2011
}

J Walker (jean.walker7@nhs.net) ${ }^{1}$, S Huc ${ }^{1}$, K Sinka ${ }^{2}$, A Tissington ${ }^{1}$, K Oates ${ }^{1}$

1. Health Protection, NHS Highland, Inverness, Scotland, United Kingdom

2. Health Protection Scotland, Glasgow, Scotland, United Kingdom

Walker J, Huc S, Sinka K, Tissington A, Oates K. Ongoing outbreak of mumps infection in Oban, Scotland, November 2010 to January 2011. Euro Surveill. 2011;16(8): pii=19803. Available online: http://www.eurosurveillance.org/ViewArticle.aspx?Articleld=19803

We report on an ongoing outbreak of 119 cases of mumps virus infection in the Oban area of Scotland, from 29 November 2010 to 31 January 2011. The median age of cases was 20 years, with the highest incidence in the 13-19-year-olds. A total of 53 cases had received two doses of measles-mumps-rubella (MMR) vaccine, in accordance with the United Kingdom vaccination schedule, while 33 had received only one dose and 30 had not been vaccinated.

\section{Outbreak description}

NHS Highland Health Protection Team in Scotland was notified on 29 November 2010 of one case of mumps in Oban, a rural coastal town, with a population of around 8,000 , on the west coast of Scotland. There were no further cases for a two-week period, but by 20 December an outbreak in Oban was obvious, with 23 cases. Many of the cases were notified around the Christmas holiday period when young people returned from work and university in urban areas.

Following the identification of the ongoing outbreak, all the general practitioner (GP) practices in the Oban area were subsequently contacted by telephone and requested to notify all cases of mumps virus infection promptly to Health Protection.

By 31 January 2011, a total of 119 cases had been notified in the Oban area (Figure 1). These represented more notifications than for the rest of Scotland for the same period (9o cases in a population of $5,168,500$ individuals). Of the 119 cases notified in Oban, 18 were laboratory confirmed and 101 were clinically diagnosed, by local GPs (based on those presenting with typical clinical features, including parotitis after 29 November).

\section{Background}

Mumps, an infection caused by a paramyxovirus, is characterised by parotitis. It may also cause orchitis, pancreatitis and meningitis, among other clinical features. In Scotland, mumps is a notifiable disease and is reported electronically to health boards by clinicians, in particular by general practitioners.
Mumps immunisation was introduced in the United Kingdom (UK) in 1988 as a single dose of measlesmumps-rubella (MMR) vaccine, for those aged 12-15 months. Before 1988, mumps virus caused outbreaks among 5-9-year-olds every three years. They would now be aged 23 years and over. In 1996 a two-dose schedule was introduced: the first dose is given to children aged 13 months and the second dose is given from the age of 3 years and 4 months onwards [1].

Current vaccination uptake rates for the first dose of MMR vaccine at 24 months (for the year ending 31 March 2010) were $93.7 \%$ for Scotland and $91.5 \%$ for the Argyll area (in which Oban is located). However, in the years post 1998, following vaccine controversy, which surrounded an alleged link between autism and the MMR vaccine, the uptake rates fell, reaching a low level in Scotland of $88.5 \%$ and in Argyll of $85.6 \%$ in 2003 [2]. This cohort, who would have been due vaccination in 1998-2003, would now be 8-14 years old.

Following a large outbreak of mumps which affected the whole of the UK in 2005, the number of cases fell until 2009, when an increase was seen again (personal communication, Katy Sinka, January 2011). In Scotland this increase has been characterised by periodic, localised occurrences of mumps cases: the outbreak reported here is the latest. Recently, there have been reports of outbreaks of mumps in other parts of the UK and other countries [3-5].

\section{Procedures following notification}

Once a mumps case is notified, oral fluid testing kits are routinely sent to GP practices for laboratory confirmation of the clinical diagnosis and epidemiological surveillance. The primary care team then contact the patient and recall them for testing. Samples are then sent to the Centre for Infections, Health Protection Agency, London. For the first notified cases in the Oban outbreak, laboratory kits were sent out. Once laboratory confirmation had been received on the first 12 of these cases, we suspended testing and recorded cases that had been notified on the basis of clinical diagnosis alone. The clinicians involved were confident 


\section{FIGURE 1}

Mumps cases by date of symptom onset, Oban outbreak, Scotland, November 2010-January 2011 (n=119)

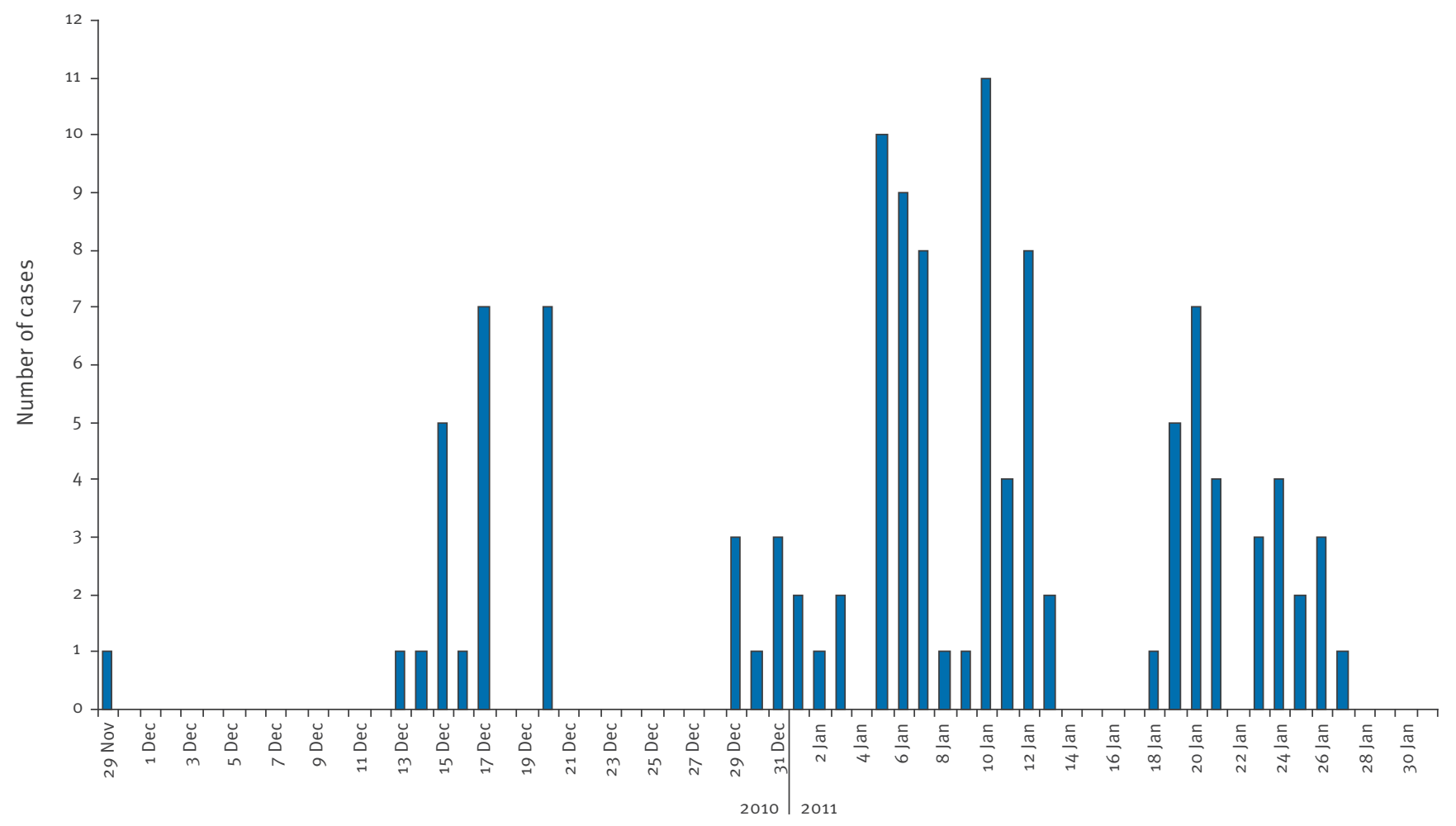

Date of symptom onset

\section{FIGURE 2}

Mumps cases by age and measles-mumps-rubella vaccination status, Oban outbreak, Scotland, November 2010January 2011 (n=119)

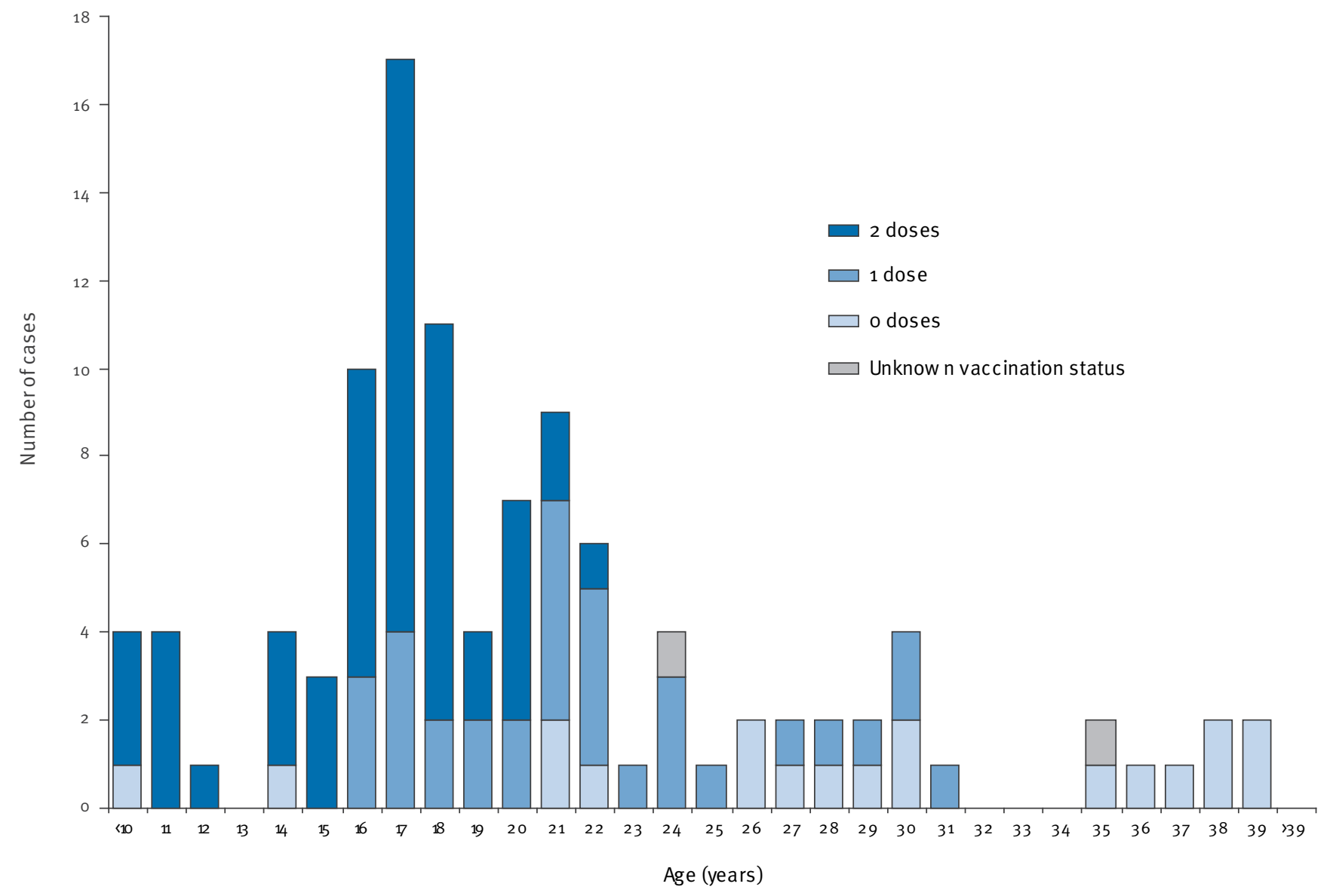


of their diagnosis and for small practices, extra testing seemed unduly burdensome.

Vaccination status is not routinely recorded when mumps cases are notified. However, given the excess number of cases from 13 to 17 December 2010 (when 15 cases were notified), the Health Protection Team contacted the relevant practices and enquired about the vaccination status of each individual and the date of vaccination. The team also enquired initially about the batch numbers of each vaccine, but it became apparent that the cases were not linked to any particular vaccine batch and that vaccinations had been given over several years by a range of primary care staff.

Towards the end of January 2011, as cases continued to be notified, it was agreed following discussion with primary care colleagues, that parents of children aged 5 to 18 years would be contacted by a letter from each GP practice involved and reminded of the offer for children to be vaccinated with two doses of MMR vaccine. At this moment in time we do not have information on vaccine uptake following the letter sent.

\section{Case information}

Of the 119 cases, 63 were females and 56 males. The age range of cases was 4 to 71 years: 85 of the cases were in the 13-29 age group and 12 were aged over 40 years. Anecdotal information revealed three cases with complications (orchitis, pancreatitis). However more detailed information on complications overall is currently being evaluated.

By 31 January 2011, vaccination status was known for 116 of the 119 cases: 53 had received two doses of MMR vaccine, 33 had received only one dose and 30 received no doses (Figure 2). For those who had one dose, the date of vaccination ranged from 5 December 1988 to 23 February 2009. For those who had received two doses, the vaccinations dates ranged from 28 September 1989 for the first dose to 13 May 2008 for the second dose.

The majority of the cases aged under 22 years had received two doses of MMR vaccine (53 of 80). Among the nine cases aged 12 years or under, eight had received two doses; among the 49 cases aged between 13 and 19 years, 37 had received two doses and 11 one dose.

Anecdotally, it appears that the index case may have been a student at one of Scotland's main universities who had returned home for the holidays. Many of the initial cases had subsequently attended a school dance and a large party in Oban. There was no common link with place of residence.

Cases continue to be notified but the rate of notifications has decreased. The peak date of symptom onset for cases was 10 January, when 11 cases were notified. By 31 January 2011, there were 18 laboratory-confirmed cases, the rest were clinically diagnosed.

\section{Discussion}

Some GPs reported that not all those affected presented to GP practices and our numbers may therefore be an underestimate. On the other hand, we applied a non-specific case definition which led to wide inclusion of cases.

Initial concerns regarding a historical problem with a vaccine batch were soon discarded as the date ranges for the first and second vaccinations were wide and vaccinations were given in different practices by different individuals and there was no link with any particular vaccine batch numbers.

The main limitation in our study is the low number of laboratory-confirmed cases. We felt that after the initial tranche of cases, clinical diagnosis was adequate and this was undertaken by several different primary care teams (101 of the 119 were clinically diagnosed). The laboratory has confirmed that the strain involved is genotype $\mathrm{G}_{5}$ in common with all strains currently seen in the UK (personal communication, Kevin Brown, 10 February 2011).

MMR vaccination coverage was affected by adverse publicity some years ago and uptake rates fell to a low of $85.6 \%$ in 2003 in the Oban area. Unvaccinated individuals, plus those who were immunised but in whom protection had subsequently waned, combined to provide a cohort of vulnerable individuals who were infected in this outbreak. The $45 \%(n=53)$ of notified cases who had received two doses of MMR vaccine is higher than the $29 \%$ of cases reported in England and Wales in 2010 [3] and the 31\% reported in England in 2004-05 [7] but lower than the 61\% noted in the Netherlands in 2010 [8] and the $75 \%$ reported in New Jersey, United States in 2009-10 [4]. If we look at the 13-19 years age group in our study - the most affected age group $-76 \%(n=37)$ had received two doses of MMR.

Published estimates of MMR vaccine efficacy to protect against mumps vary. It has been reported as $88 \%$ (95\% confidence intervals (Cl): $83 \%$ to $91 \%$ ) for one dose and $95 \%$ ( $95 \% \mathrm{Cl}: 93 \%$ to $96 \%$ ) for two doses [7]. In addition, two doses of vaccine were reported as being more effective ( $88 \%$ (95\% Cl: $62 \%$ to $96 \%)$ than a single dose $(64 \%$ (95\% Cl: $40 \%$ to $78 \%)$ ) [9]. Furthermore, Cohen et al. report waning immunity in older vaccinated individuals [9].

Although the numbers in our cohort are small, they add to the growing body of evidence which suggests that immunity to mumps virus may wane over time $[4,7-9]$.

These cases highlight the importance of ensuring high uptake of the recommended two doses of MMR. They also imply a need for further research into longterm mumps immunity among those partially or fully vaccinated in order to inform future immunisation programmes. 


\section{Acknowledgements}

We wish to thank Lorraine McKee, Health Protection, NHS Highland and Judith Tait, Information Services Division. We would also like to thank Pauline Jespersen, Lorn Medical Practice and all the GPs and patients in the Oban area for their help.

\section{References}

1. United Kingdom Department of Health (DH). Immunisation against infectious disease. London:HMSO, 1996. [Accessed 2 Feb 2011]. Available from: http://www.dh.gov.uk/prod_ consum_dh/groups/dh_digitalassets/@dh/@en/documents/ digitalasset/dh_4072984.pdf

2. NHS National Services Scotland. Information Services Division (ISD). Child Health. Immunisation. [Accessed 9 Feb 2011]. Available from: http://www.isdscotland.org/isd/5705.html

3. Yung C, Bukasa A, Brown K, Pebody R. Public health advice based on routine mumps surveillance in England and Wales. Euro Surveill. 2010;15(38):pii=19669. Available from: http:// www.eurosurveillance.org/ViewArticle.aspx?Articleld=19669

4. Centers for Disease Control and Prevention (CDC). Update: Mumps Outbreak - New York and New Jersey, June 2009 January 2010. MMWR Morb Mortal Wkly Rep. 2010;59(5):125-9.

5. Donaghy M, Cameron JC, Friederichs V. Increasing incidence of mumps in Scotland: Options for reducing transmission. J Clin Virol. 2006 Feb;35(2):121-9.

6. Health Protection Scotland (HPS) Weekly Report. Mumps cases in NHS Highland area - Oban. Glasgow:HPS. 26 Jan 2011. Available from: http://www.documents.hps.scot.nhs.uk/ewr/ pdf2011/1104.pdf

7. Cohen C, White JM, Savage EJ, Glynn JR, Choi Y, Andrews N, et al.Vaccine effectiveness estimates, 2004-2005 mumps outbreak. England. Emerg Infect Dis. 2007;13(1):12-7.

8. Whelan J, van Binnendijk R, Greenland K, Fanoy E, Khargi M, Yap K, et al. Ongoing mumps outbreak in a student population with high vaccination coverage, Netherlands, 2010. Euro Surveill. 2010;15(17):pii=19554. Available from: http://www. eurosurveillance.org/ViewArticle.aspx?Articleld=19554

9. Harling R, White JM, Ramsay ME, Macsween KF, van den Bosch $C$. The effectiveness of the mumps component of the MMR vaccine: a case control study. Vaccine. 2005;23(31):4070-4. 